\title{
ESIGN OF A TORQUE GENERATING MECHANISM
}

\author{
G. Aragón-González, A. Canales-Palma, A. León-Galicia, J. R. Morales-Gómez
}

ABSTRACT

The design and assembly of a mechanism to bend schedule 80 stainless steel pipe up to $1 \frac{1 / 2}{2}$ in nominal diameter is presented. The use of a relatively small hydraulic actuator, coupled with a toothed wheel to produce the bending torque, is a novel approach to the process. The bending method uses two arms and a radius block in order to accomplish the bending. The hydraulic power consumption in the machine is very small (750 W, 3.4 MPa, $11.4 \mathrm{in} / \mathrm{min})$. The strongest restriction upon the design is that it could be manufactured in small shops, with a cost low enough to be profitable even for a small production volume.

\section{RESUMEN}

Se presenta el diseño y construcción de un mecanismo para doblar tubo de acero inoxidable, hasta de $1 \frac{1}{2}$ pulg de diámetro nominal y cédula 80 . El sistema fue ideado para pequeñas industrias, que requieren una producción moderada con bajo costo. Emplea una unidad de potencia hidráulica muy reducida (750 W, 3.4 $\mathrm{MPa}, 11.4 \mathrm{in} / \mathrm{min}$ ). Para doblar el tubo se emplea el método de doblado guiado. El par torsor se genera con un mecanismo novedoso de rueda dentada y un actuador lineal hidráulico. El tubo se sujeta a un dado de sujeción y un dado guía permanece fijo; el doblado se forma sobre el perímetro de este dado.

KEYWORDS: Torque, mechanisms, bending of pipes.

\section{INTRODUCTION}

The manufacturing industry is in need of torque producing devices for the bending of pipes structural profiles, metal sheets, etc. Those that can be obtained in the market are expensive, foreign, and for serial production or continuous use. The national industry conditions do not need high production units, due to the market volume sale. However, it requires the quality that offers a process with controlled parameters.

In view of the aforementioned conditions, a machine for the bending of thick wall pipes is proposed. The design restraints include: construction by a small shop; low cost; easy operation; a generating torque capable of bending stainless steel up to $1 \frac{1}{2}$ inch nominal diameter, schedule 80 wall thickness pipe.

The machine should be equipped with accessories to bend pipes of several nominal diameters up to $11 / 2$ inch, and a unit capable of generating a bending torque. This work is aimed to the design of this unit.2. [RTM] WORKING PRINCIPLE.

The required unit, in accordance with the mentioned specifications for the machine, should produce a torque capable of bending a $1 \frac{1}{2}$ inch diameter, AISI 201 stainless steel, thick walled pipe. The guided bending was selected as the manufacturing process. In this process, the part to be bent is fixed at to different arms. One arm is kept fixed and the other is made rotate in a circular path in a way as to produce the specified bent. This is shown in Figure 1. 


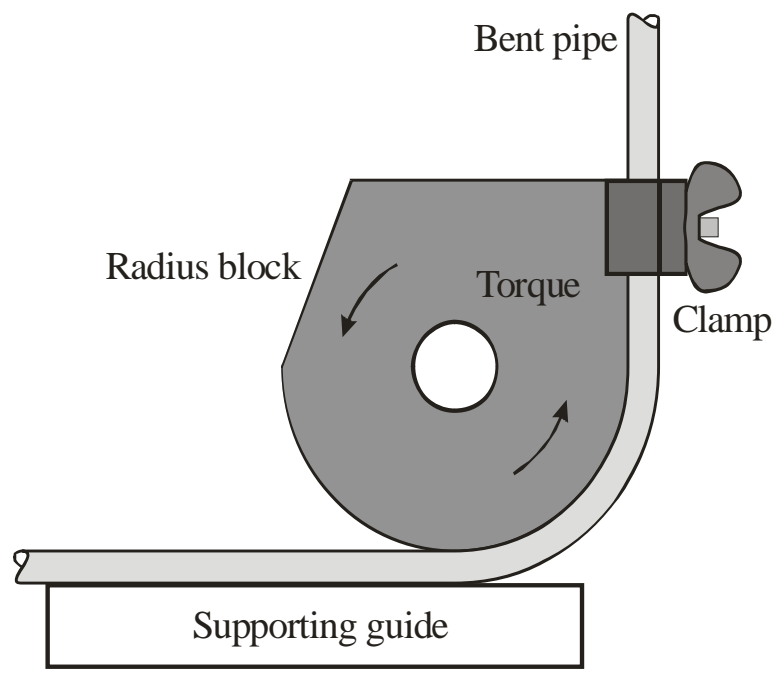

Figure 1. Guided bending process

It can be seen from Figure 1, where and how to apply the torque or the force, at a determined distance as to produce the required deformation. Therefore, the problem could be reduced to the design of a device that could move the part attached to the movable arm, in order to obtain the demanded bending.

\section{BENDING TORQUE PROVIDER.}

There are several choices in order to generate the bending torque, from the simplest obtained by a lever and fulcrum to a hydraulic torque generation unit [1], [6]. In accordance with the device specifications, the process must be such as to produce a constant continuous couple to avoid imperfections in the forming of the piece; for this reason, the use of a manual applied force is discarded.

A hydraulic device for the torque generation was unacceptable due to the cost. Finally, it was decided to use a linear actuator and a toothed wheel, with several accessories as to make the torque generating for bending pipe acceptable. The proposed arrangement is depicted in Figure 2. [RTM]

The acceptance of this arrangement allows a torque generation mechanism by using a relatively small hydraulic power unit $\left(\mathrm{W}=750[\mathrm{~W}] ; p_{\max }=3.45[\mathrm{MPa}] ; \mathrm{Q}=12[\mathrm{l} / \mathrm{m}]\right)$, where the mass flow fixes the velocity of the process and the pressure the torque produced. [RTM]

The required torque is given by [2]

$$
\tau_{D}=\frac{\pi}{32}\left[\frac{D^{4}-d^{4}}{D}\right] \sigma_{y}
$$

where:

$\mathrm{D}=$ Outside pipe diameter $[\mathrm{m}]$

$\mathrm{d}=$ Inside pipe diameter $[\mathrm{m}]$

$\sigma_{\mathrm{y}}=$ Material yielding stress $[\mathrm{Pa}]$

$\tau_{\mathrm{D}}=$ Bending torque $[\mathrm{N} . \mathrm{m}]$.

If the material to be bent is AISI 201 steel, with a 758 [MPa] yielding stress, and the nominal diameter of the pipe is $11 / 2$ inch, schedule $80(D=0.0483 \mathrm{~m} ; d=0.0381 \mathrm{~m})$, the maximum bending torque is 5118 [N$\mathrm{m}]$. 


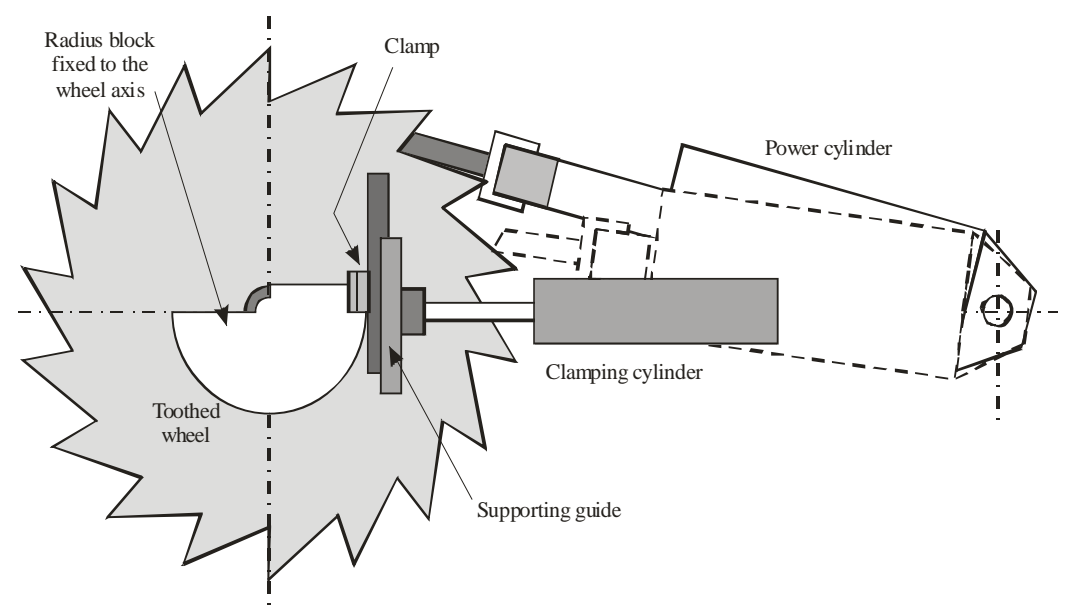

Figure 2. Pipe bending mechanism

\section{TOOTHED WHEEL.}

The heart of the bending device is a toothed wheel moved by a hydraulic lineal actuator in order to generate the torque. The wheel was divided into 18 sectors, $20^{\circ}$ each. The toothed wheel shaft turns $20^{\circ}$ with every actuator stroke. No reference to such a way to produce a torque was found in the literature (see Figure 2). This solution presented some design problems that would be dealt with in what follows.

The root radius (at the base of the teeth) is $209 \mathrm{~mm}$; a lesser dimension would reduce the torque generated by the force proportioned by the actuator. To avoid the follower from sliding out of the tooth, the angle of the face in contact with the follower should be less than $90^{\circ}$, taking as reference the normal to the tangent in the root of the tooth, when the axis is that of the power cylinder (see figure 3 ).

In order to transmit the force uniformly, the thickness of the face in contact with the follower is equal to the diameter of the actuator's rod; that is, $25 \mathrm{~mm}$ (1 in). A disk $25 \mathrm{~mm}$ thick was required in order to resist the shearing stress generated by the cylinder. To couple the transmission shaft with the wheel, a $51 \mathrm{~mm}$ hole was machined into the center of it. Four Woodruff keys evenly spaced were placed in the shaft and hole coupling, as to ensure that they rotate as a solid body. The keys dimensions are $1 / 4$ in by $1 / 2$ in [3]. 


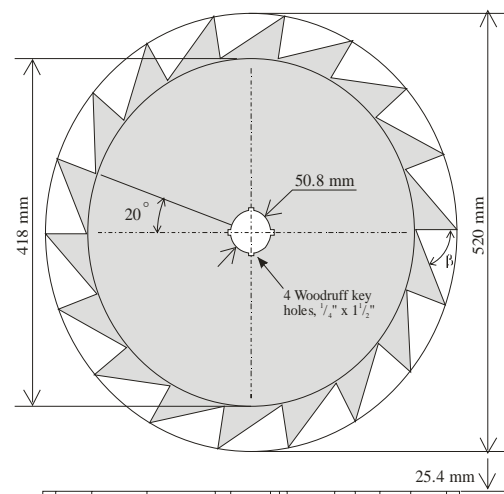

Figure 3. Toothed wheel

The wheel was manufactured using a tracer-pantograph coupled with an arc-plasma cutting torch, since the finishing requirements for the contact surface are fulfilled with this process, and the cost is the lowest of the similar manufacturing processes [4].

\section{SHAFT TRANSMITTING POWER.}

The torque generated by the hydraulic actuator and the toothed wheel is transmitted to the movable arm so as to perform the bending. The design of the shaft shows that $51 \mathrm{~mm}$ diameter, $1018 \mathrm{steel}$ [5] is sufficient to carry the torque. The shaft is also loaded with a flexural moment due to the force applied by the cylinder; this load is taken by the supporting bearings on the shaft.

\section{FOLLOWER.}

The hydraulic actuator needs an interface that provides the contact between the rod of the actuator and the teeth of the wheel. To this purpose, a follower was designed. This part is depicted in Figure 4. It has a female thread, $1 \frac{1}{2}$ in diameter, $12 \mathrm{UNC}-2 \mathrm{~A}$ and $40 \mathrm{~mm}$ depth [4], to suit a corresponding male thread on the tip of the rod. The other end of the follower has a tip with a $67^{\circ}$ plane as shown, in order to avoid interference with the teeth of the wheel.

\section{HEAD OF THE SHAFT AND BASE OF THE RADIUS BLOCK.}

The radius block is mounted by means of two off-center bolts, fixed to a plate that rotates around the transmission shaft. This plate transmits the torque to the radius block by means of the high resistance off-center bolts. The dimension and location of the bolts and rotating axis is shown in Figure 5.

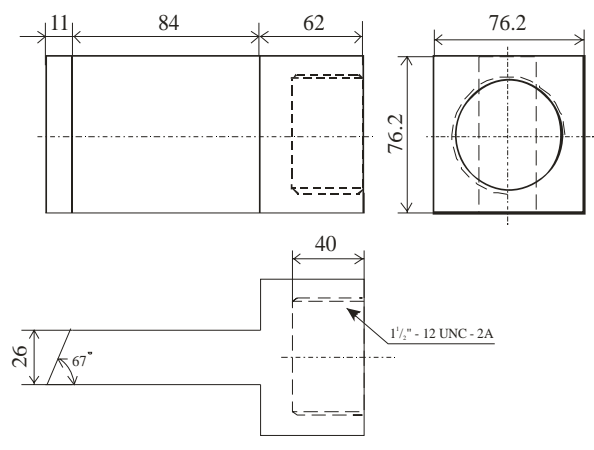

Figure 4. Follower 

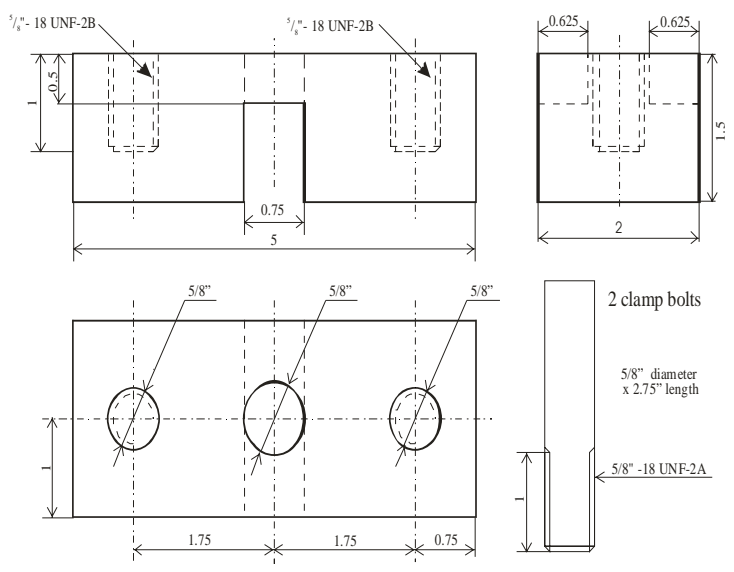

Figure 5. Fixing plate

Alignment of the base plate and the radius block is obtained by means of a central axis that is a part of the transmission shaft carefully turned (see Figure 6).
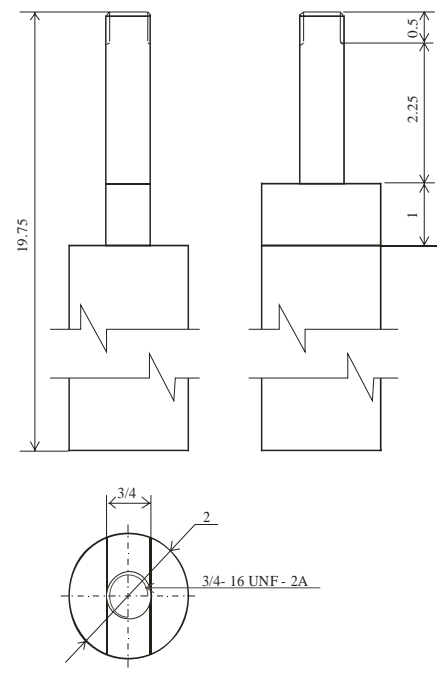

Figure 6. Radius block central axis

\section{MECHANISM ASSEMBLY.}

The assembly of the mechanism is shown in Figure 7. The toothed wheel is perpendicularly mounted on top of a steel plate, by means of properly selected bearings. On this surface, the radius block, the fixed and movable arms, the ratchet and the cylinder that provides the clamping of the pipe to be bent are also mounted. 


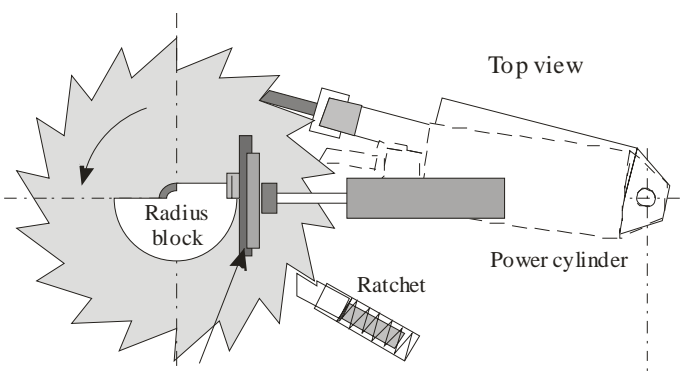

Supporting guide

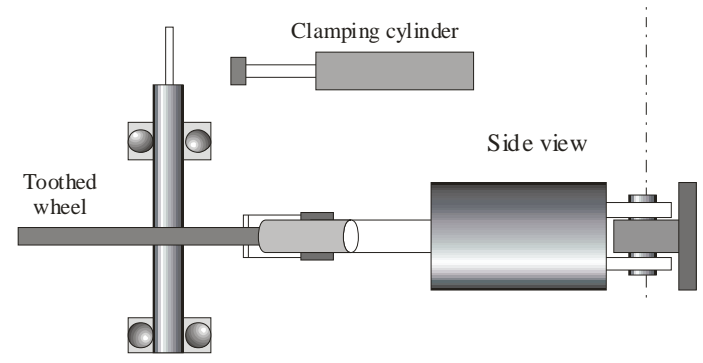

Figure 7. Mechanism assembly

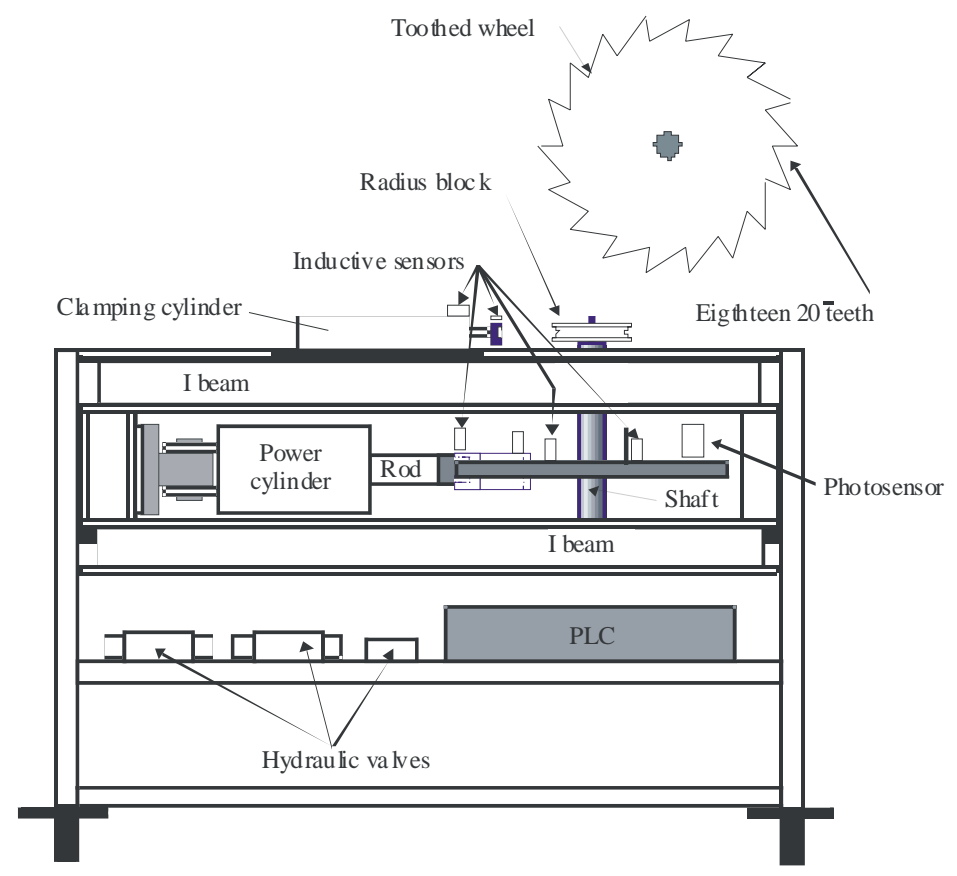

Figure 8. Pipe bending device 


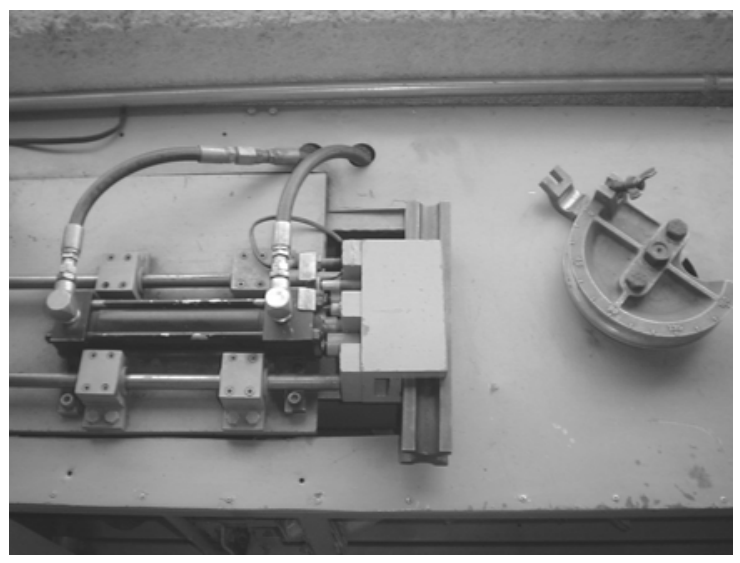

Figure 9. Real pipe bending mechanism

\section{CONCLUSIONS.}

A novel design of a mechanism for bending pipe is presented. As a first attempt, some aspects of the design could be changed but only after the building and testing of the device (Figures 8 and 9). It satisfies the restrictions posed and could be constructed with supplies easily found in the local market. The manufacturing processes involved in the manufacture are well known and at the reach of any small shop. Therefore, it can be concluded that the pursued goal has been accomplished.

\section{REFERENCES}

[1] Parker Hannifin Co. "Parker actuator products". Cleveland, Ohio, (1989).

[2] F. Beer y R. Johnston. "Mecánica de materiales". México, McGraw-Hill. (1982).

[3] Artobolevski. "Mecanismos en la técnica moderna". México, MIR, 1a. ed. (1982).

[4] J. Shigley. "Diseño en ingeniería mecánica". McGraw-Hill, 4a. ed. México (1990).

[5] Marks. "Manual del ingeniero mecánico". México, McGraw-Hill, 2a. ed., (1992).

[6] Parker Hannifn Co "Hydraulics products and total svstems engineering". Cleveland, Ohio, (1989).

Acknowledgements

This work was supported by the Program for the Professional Development in Automation, through the grant from the Universidad Autónoma Metropolitana and Parker Haniffin - México. 
Authors Biography

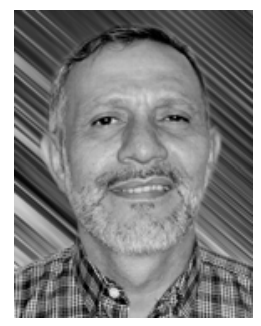

\section{M. en C. Gerardo Aragón González}

He earned a B.S. in physics and mathematics (1975) and a MS in mathematics both at the Instituto Politécnico Nacional (IPN), Mexico City. He has been a Full Professor in the Energy Department at the Universidad Autónoma Metropolitana-Azc, Mexico City since 1974 and a member of the Program for the Professional Development in Automation since 1992, through the grant from the Universidad Autónoma Metropolitana and Parker Haniffin-México. His current interest lies in the application of control motion, thermofluids and numerical optimization.

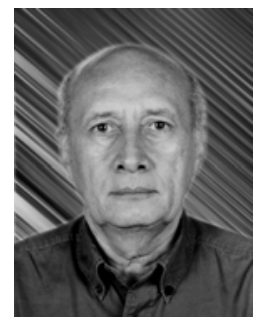

\section{M. en C. Aurelio Canales Palma}

He earned a B.S. in physics and mathematics (1966) and a MS in mathematics both at the Instituto Politécnico Nacional (IPN), Mexico City. He has been a Full Professor in the Energy Department at the Universidad Autónoma Metropolitana-Azc, Mexico City since 1973 and a member of the Program for the Professional Development in Automation since 1992, through the grant from the Universidad Autónoma Metropolitana and Parker Haniffin-Mexico. His current interest lies in the application and development of control motion, thermofluids and numerical optimization. 


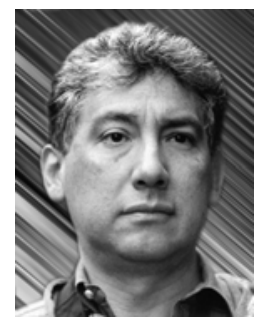

M. en C. Alejandro León Galicia

He earned a B.S. in mechanical engineering (1980) at the Universidad Autónoma Metropolitana-Azc, Mexico City. He obtained a MS in mechanical engineering (1997) at the Instituto Politécnico Nacional (IPN), Mexico City. He has been a Full Professor in the Energy Department at the Universidad Autónoma Metropolitana-Azc, Mexico City since 1982 and a member of the Program for the Professional Development in Automation since 1992, through the grant from the Universidad Autónoma Metropolitana and Parker Haniffin-México. His current interest lies in the application of control motion, thermofluids and numerical optimization.

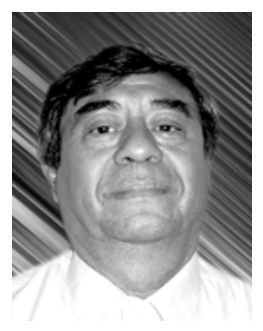

\section{Dr. Juan Ramón Morales Gómez}

He earned a B.S. in mechanical engineering (1968) at the Instituto Politécnico Nacional (IPN), Mexico City. He obtained a MS in mechanical engineering at the University of North Dakota in Grand Forks, ND and a Sc. D. at the New Mexico State University in Las Cruces, NM in 1974. He has been a Full Professor in the Energy Department at the Universidad Autonoma Metropolitana-Azc, Mexico City since 1974 and a member of the Program for the Professional Development in Automation since 1992, through the grant from the Universidad Autónoma Metropolitana and Parker Haniffin-Mexico. His current interest lies in the application of control motion, solar energy and refrigeration. 